\title{
Value of Autofluorescence Imaging Videobronchoscopy in Detecting Lung Cancers and Precancerous Lesions: A Review
}

\author{
Qing He MD, Qing Wang MD, Qi Wu MD, Jing Feng MD PhD, \\ Jie Cao MD, and Bao-Yuan Chen MD \\ Introduction \\ Development of AFB \\ Mechanisms of Different Autofluorescence Intensities in Normal \\ and Cancerous Tissue \\ Diagnostic Performance of AFI Versus WLB \\ Diagnostic Performance of AFI Versus Other AFBs \\ Diagnostic Performance of AFI Versus Narrow-Band Imaging \\ Summary
}

\begin{abstract}
Bronchoscopy technology is a desirable method for detecting lung cancers arising in the central airways. Most early cancers and precancerous lesions are not visible on conventional white-light bronchoscopy (WLB). Autofluorescence bronchoscopy (AFB) is a newly developed technology that exploits the difference in autofluorescence intensity between normal and tumorous tissues to detect bronchial cancers and precancerous lesions. Several types of AFB systems have been used in clinical practice, and autofluorescence imaging videobronchoscopy (AFI) is one of these AFBs. In most of the studies on AFB other than AFI, AFB has provided a much higher sensitivity but a lower specificity than WLB. Regarding AFI, recent studies have reported controversial results on the sensitivity and specificity for detecting cancers and precancerous lesions, compared with WLB. In this paper we describe the working mechanisms and characteristics of AFBs, mainly AFI, and the diagnostic performance of AFI, compared with WLB, other AFBs, and narrow-band imaging, for detecting lung cancers and precancerous lesions. Key words: autofluorescence imaging videobronchoscopy; autofluorescence bronchoscopy; white-light bronchoscopy; narrow-band imaging; lung cancer; precancerous lesion. [Respir Care 2013;58(12):2150-2159. (C) 2013 Daedalus Enterprises]
\end{abstract}

\section{Introduction}

Lung cancer is the most common cause of cancer-related death worldwide, with more than 1.3 million people

Dr He is affiliated with the Department of Endocrinology, Tianjin Medical University General Hospital, Tianjin, China. Dr Wang MD is affiliated with the Tianjin Medical University Graduate College, Tianjin, China. Dr Wu is affiliated with the Respiratory Department, Tianjin Haihe Hospital, Tianjin, China. Drs Wang, Feng, Cao, and Chen are affiliated with the Respiratory Department of Tianjin Medical University General Hospital, Tianjin, China. Dr Feng is also affiliated with the Division of Pulmonary and Critical Care Medicine, Duke University Medical Center, Durham, North Carolina. Drs He and Wang are co-first authors. dying of lung cancer annually. ${ }^{1}$ The prognosis of patients with lung cancer is strongly associated with the disease

\footnotetext{
This study was supported by grants 81270144,30800507 , and 81170071 from the National Natural Science Foundation of China. The authors have disclosed no conflicts of interest.

Correspondence: Jing Feng MD PhD, Respiratory Department, Tianjin Medical University General Hospital, Tianjin, China 300052. E-mail: jing.feng2@ duke.edu. Jie Cao MD, Respiratory Department, Tianjin Medical University General Hospital, Tianjin, China 300052. E-mail: tjcaojie@sina.com.
}

DOI: $10.4187 /$ respcare. 02524 


\section{Value of Autofluorescence Imaging Videobronchoscopy}

stage at the time of diagnosis. The 5-year survival rate for patients with stage IA is about $70 \%$; however, for those with stage II, III, or IV the rates range from $40 \%$ to less than $5 \% .^{2}$ Bronchoscopy technology is a desirable method for detecting lung cancers arising from the central airways. Early cancers and precancerous lesions are subtle, with a surface diameter of only a few millimeters, and they often lack characteristics that would make them visible on conventional white-light bronchoscopy (WLB). Only 29\% of carcinoma in situ and 69\% of microinvasive tumors are identified endoscopically with WLB, even by experienced bronchologists. ${ }^{3}$

Recent advances in molecular biology suggest a multistep theory of carcinogenesis. ${ }^{4}$ As dysplasia might be one premalignant condition, early detection and follow-up of these lesions are essential. Bota et al reported the alteration of premalignant bronchial lesions followed for 2 years with bronchoscopy technology. ${ }^{5}$ During 2 years, 6 of 169 low grade epithelial lesions progressed to persistent severe dysplasia; 10 of 27 severe dysplastic lesions and 28 of 32 carcinomas in situ progressed. A study showed that highgrade pre-invasive lesions had a high chance of progressing to invasive cancer. ${ }^{5}$ Another study showed ${ }^{6}$ that most carcinoma in situ ultimately became microinvasive. It has also been shown that the identification and treatment of pre-invasive lesions in other organs, such as the cervix and colon, can significantly improve cancer related mortality. ${ }^{7,8}$ So, overcoming the difficulty WLB has in identifying early mucosal lesions is meaningful and clinically important. Meanwhile, we have to accept that early diagnosis of dysplastic lesions, to some extent, adds to confusion and decreases quality of life due to a possibly unnecessary fear of malignancy in some patients.

AFB is an advanced technology that exploits the autofluorescent nature of bronchial mucosa to detect tiny and subtle superficial lesions. In the past 3 decades, AFB has been applied to detect early-stage carcinomatous lesions through endoscopy workstation..$^{9,10}$ Several types of AFB systems have been designed, developed, and marketed, including the LIFE system (Xillix Technologies, Richmond, British Columbia, Canada), the D-Light system (Karl Storz, Tuttlingen, Germany), and the SAFE system (Pentax, Tokyo, Japan). In comparison with conventional WLB, these AFBs provide a much higher sensitivity, which is interesting and exciting, but at the same time, the specificity is lower, ${ }^{11-18}$ which is, obviously, an important disadvantage.

One type of AFB, autofluorescence imaging videobronchoscopy (AFI is its trademark name), was developed by Olympus Medical Systems, Tokyo, Japan. Some studies have found that AFI is better than WLB for detecting superficial cancers and precancerous lesions, ${ }^{19-23}$ whereas some other studies have reported controversial results. ${ }^{24} \mathrm{In}$ this paper we describe the working mechanisms and char- acteristics of AFBs, mainly AFI, and the diagnostic performance of AFI for detecting lung cancers and precancerous lesions.

\section{Development of AFB}

When the bronchial surface is illuminated by light, the light can be reflected, back-scattered, absorbed, or induce tissue autofluorescence. Tissue autofluorescence is not visible to the unaided eye, because its intensity is very low and overwhelmed by the reflected and back-scattered light. However, with suitable instrumentation the tissue autofluorescence can be visualized. ${ }^{25}$ The intensity of the autofluorescence differs substantially between normal and tumorous tissues, which allows visualization of cancers and precancerous lesions in bronchi. ${ }^{26-29}$

The LIFE system, which was designed by Lam et al, in Vancouver, British Columbia, Canada, ${ }^{28,30}$ consists of a light source (helium-cadmium laser, wavelength $442 \mathrm{~nm}$ ), image intensifier (charge-coupled device [CCD] camera with green and red filters), and imaging console. The $442 \mathrm{~nm}$ wavelength radiation produces a blue light, delivered to the bronchial tissue surface through an endoscope. The autofluorescence emitted from the tissue is detected by the camera, which has 2 CCDs that capture green and red autofluorescence, and the images are immediately processed and displayed on the monitor as a color image. Normal bronchial mucosa appears green, while cancers and pre-invasive lesions appear brown, or brown-red.

Storz and Pentax independently developed the D-Light system, which uses a modified xenon light source, a filter in the ocular of the bronchoscope, and an optional integrating camera. The filter in the ocular of the bronchoscope transmits red and green wavelengths, together with a narrow band within the excitation wavelength, which allows visualization of low autofluorescence. ${ }^{31}$ The fluorescence images can be viewed directly through the eyepiece or displayed on a monitor connected to the camera, and abnormal tissue appears red/brown against a normal gray/blue background. ${ }^{32}$

The SAFE 1000 system uses a xenon light instead of laser light. Infrared light is eliminated by an infrared filter, and only $420-480 \mathrm{~nm}$ excitation light is allowed through the filter and transmitted to the image processor. Normal mucosa appears green, and abnormal mucosa areas show a cold image caused by the lack of autofluorescence.

The first and still most commonly used AFB systems are based on fiberoptic bronchoscopes with CCD cameras. As fiberoptic bronchoscopy has been replaced by videoendoscopy at most bronchoscopy facilities, autofluorescence diagnosis systems integrated into videoendoscopes have been developed. Videobronchoscopes yield highresolution images and increase optical sensitivity and specificity. Two video-autofluorescence systems are currently 


\section{Value of Autofluorescence Imaging Videobronchoscopy}

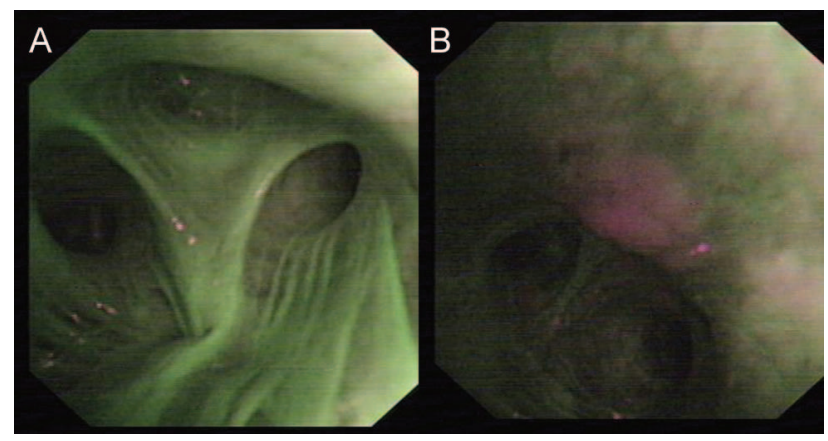

Fig. 1. Autofluorescence imaging videobronchoscopy in a 61year-old male with small cell lung cancer confirmed via pathology. A: Right upper lobe shows no mucosal abnormalities: all the mucosa appears green. B: Left upper lobe shows the magenta color that indicates mucosal abnormality.

available, the SAFE 3000 and AFI systems. The SAFE 3000 system uses both a xenon lamp, for white-light imaging, and a monochromatic diode laser, for autofluorescence imaging. As both light sources are available at the same time, the system enables immediate simultaneous viewing of both white-light video and AFB images. ${ }^{33}$ Normal bronchial tissue emits intense green autofluorescence when excited by blue light from a diode laser $(408 \mathrm{~nm})$, so normal mucosa appears green and abnormal mucosa lacks this green autofluorescence and appears dark.

AFI is a newly developed AFB system that consists of 3 parts: an autofluorescence videobronchoscope (BF-F260, generally), a video processor unit Evis Lucera Spectrum (CV-260SL), and a xenon light source. The AFI image is presented on a 48-cm monitor (OEV-191). The system transmits 3 wavelengths: excitation blue light (395-445 nm, to induce autofluorescence), $550 \mathrm{~nm}$ (red reflected light), and $610 \mathrm{~nm}$ (blue reflected light). ${ }^{19}$ Normal mucosa appears green (Fig. 1A), inflammation appears blue (because it contains a high concentration of hemoglobin, which absorbs the green and red wavelengths), and cancers and precancerous lesions appear magenta (see Fig. 1B), because they mix red/blue reflected signals and lack the green autofluorescence signal.

\section{Mechanisms of Different Autofluorescence Intensities in Normal and Cancerous Tissue}

Although the precise mechanisms of the different autofluorescences of normal and cancerous tissues have not been established, some have been considered: autofluorescence can change if the epithelial layer thickens, as in the presence of cancer, or if the concentrations of certain substances in the tissue, including fluorophores and nonfluorescent chromophores, change.

Autofluorescence is intensely produced by submucosal stroma, but epithelium, mucosa, and cancerous tissue emit very little fluorescence. Because of the thicker epithelium and mucosa in a cancer lesion than in normal mucosa, or because of the presence of cancer itself, the autofluorescence is intensely absorbed. Autofluorescence of tissues can attenuate due to changes in the light-scattering process, from an increase in nuclear size, cellular density, or distribution of the cells associated with lung cancer development.

Autofluorescence tissues can also be changed if the distribution or concentration of the fluorophores changes, because AFB makes use of autofluorescence and absorption properties to provide information about the biochemical composition and metabolic state of endogenous fluorophores in bronchial tissues of central airways. ${ }^{34}$ Most endogenous fluorophores are associated with the tissue matrix, such as collagen and elastin, or are involved in cellular metabolic processes. One of the major causes for the loss of autofluorescence in areas of dysplasia or cancer is found to be a decrease in the extracellular matrix content. ${ }^{35} \mathrm{~A}$ recent study showed that a proportion of the dysplasia or cancer lesions expressed matrix metalloproteinases that could degrade the extracellular matrix. ${ }^{36}$ Fluorophores, such as porphyrin, flavins, and nicotinamide adenine dinucleotide (NADH), are involved in cellular metabolic processes. Cancerous tissue has higher metabolism than normal tissue, so its blood volume increases while oxygen concentration in the cells decreases. Because of the increase of blood volume and accumulation character specific to cancer, the amount of porphyrin is increased (red light is increased), ${ }^{34}$ and at the same time, flavin is reduced (green autofluorescence is decreased) as the oxygen concentration is decreased. NADH increases due to the increase in cellular metabolic activity. Autofluorescence of tissues can also change if the concentration of some other fluorophores, such as aromatic amino acids and lipopigments, changes.

Meanwhile, the fluorescent properties of bronchial tissues in central airways are determined by the concentration and distribution of nonfluorescent chromophores such as hemoglobin. Autofluorescence of tissues can attenuate due to increased absorption of the excitation light by hemoglobin, because of angiogenesis in cancerous or precancerous lesions.

\section{Diagnostic Performance of AFI Versus WLB}

Among the studies ${ }^{37-48}$ of AFB versus WLB for detecting cancers and precancerous lesions, most have concluded that AFB has a much higher sensitivity and a lower specificity than WLB. ${ }^{11,13,40,41}$ AFI has shown significantly higher sensitivity in almost all the studies to date. Some studies ${ }^{19,22,23,49}$ have found that AFI has superior specificity to WLB, while some other studies have found sim- 


\section{Value of Autofluorescence Imaging Videobronchoscopy}

ilar or lower specificity. ${ }^{20,21,24}$ Whether AFI can improve detection of lung cancer or precancerous lesions is still controversial.

Several studies have compared the diagnostic performance of AFI and WLB. In these studies, generally speaking, WLB was undertaken before AFI, with local anesthesia with $2 \%$ lidocaine spray, although the order of the procedures can be varied and does not affect the results. After WLB, the device is switched to AFI mode and AFI examination is performed. Still images of all sites of interest are recorded under both WLB and AFI. After examination, biopsies are taken from all suspected areas on WLB and AFI, and the biopsy specimens are fixed in $10 \%$ buffered formalin and stained with hematoxylin and eosin.

The available studies of AFI recruited patients according to different inclusion criteria. Ueno et al ${ }^{50}$ evaluated the efficacy of AFI in the diagnosis of cancers and precancerous lesions, and included patients with suspected or known lung cancers. Li et al ${ }^{20}$ conducted a prospective clinical study, and recruited patients who underwent both AFB and WLB for general diagnosis and for postoperative recheck. Herth et $\mathrm{al}^{21}$ compared the diagnostic yields of AFI, WLB, and narrow-band imaging (NBI) in the diagnosis of intraepithelial neoplasia, and included patients who were at high risk for lung cancer but had no clinical evidence of central airway malignancies. Cetti et $\mathrm{al}^{24}$ evaluated the diagnostic performance of AFI in lung cancer, and recruited patients with suspected lung cancer, and excluded patients with already diagnosed central-airway lung cancer. Zaric et al $22,23,49$ evaluated AFI in the assessment of tumor extent (margins), and recruited patients with suspected lung cancer, and excluded patients with suspected or known lung cancer metastases.

For different purposes, those studies had different biopsy strategies. Three studies by Zaric et al ${ }^{22,23,49}$ evaluated AFI for assessing tumor extent, and the biopsies were taken from the margins of the visualized pathologic mucosa. The other studies ${ }^{19-21,24,50}$ were designed to evaluate AFI in the diagnosis of cancers and precancerous lesions, and the biopsies were taken from the cores of the suspicious areas, under either AFI or WLB.

The studies had different endoscopic classifications and histologic standards. In the study by Chiyo et al ${ }^{19}$ a magenta image was classified as positive for malignant or pre-invasive lesions, and biopsies with a histology grade of dysplasia or worse were considered positive. Ueno et al ${ }^{50}$ evaluated AFI findings with a 4-point scale and evaluated WLB findings with a 3-point scale. AFI-III (images appeared magenta) and WLB-III (changes suggesting severe dysplasia and cancer) were considered positive endoscopically; biopsies with severe dysplasia or worse were considered positive histologically. Li et al ${ }^{20}$ classified endoscopic lesions into 3 grades, in AFI or WLB. AFI-II (images appeared pink or brown) and AFI-III (images appeared classic magenta) were considered abnormal, and WLB-II (hyperemia, edema, thickness, color changes, and regression or buckling of mucosal vessels) and WLB-III (granulation of the bronchial mucosa or visible neoplasm) were considered abnormal. Biopsies with a histology grade of severe dysplasia or worse were considered positive. Herth et $\mathrm{al}^{21}$ evaluated AFI and WLB findings with a 4-point scale: normal, abnormal but not suspicious, suspicious for intraepithelial neoplasia, tumor. Any lesion that was "suspicious for intraepithelial malignancy" was classified as positive on bronchoscopy for pre-invasive neoplasia. Biopsies with a histology grade of moderate to severe dysplasia or carcinoma in situ were considered positive for intraepithelial neoplasia.

Cetti et $\mathrm{al}^{24}$ graded the bronchoscopic appearance of the mucosa as normal, nonspecific abnormality/inflammatory, suspicious of cancer, or definite tumor. Lesions that were "suspicious of cancer or definite tumor" were classified as positive on bronchoscopy. Biopsies with a histology grade of moderate dysplasia or worse were considered positive. In the studies by Zaric et al,22,23 red/brownish or magentacolored areas were considered positive via AFI, and biopsies with a histology grade of carcinoma were considered positive.

We will review 8 studies that have compared the diagnostic performance of AFI to that of WLB. Table 1 describes these studies' research methods, and Table 2 describes their biopsy results and findings on the sensitivities and specificities of AFI and WLB. Seven of the studies ${ }^{19-23,49,50}$ found sensitivity of AFI significantly higher than that of WLB, whereas the remaining study 24 found the sensitivity of AFI not significantly different from WLB. Four of the studies found the specificity of AFI significantly higher than that of WLB, ${ }^{19,22,23,49}$ one found the specificity was not different from $\mathrm{WLB},{ }^{24}$ and the other 3 found the specificity of AFI significantly lower than that of WLB. ${ }^{20,21,50}$ On one hand, the diverse findings on the sensitivity of AFI can be partly ascribed to different recruitment criteria, which would lead to different incidences of pre-invasive lesions in subjects recruited in different studies. In a meta-analysis, ${ }^{18}$ the advantage of AFBs depended on the incidence of pre-invasive lesions, but not invasive cancers. Cetti et $\mathrm{al}^{24}$ found the sensitivity of AFI as low as that of WLB, and there was a trend toward lower specificity with the AFI mode $(P=.06)$, but the incidence of pre-invasive lesions in their subjects was only $6 \%$, which was significantly lower than that in other studies. In study by Lam et $\mathrm{al}^{30}$ the incidence was about $15 \%$, and Chiyo et $\mathrm{al}^{19}$ had an incidence of about $39 \%$. A fair conclusion from these data may be that the performance of AFI depends on the pre-test probability of preinvasive lesions. AFI was developed to detect pre-invasive 


\section{Value of Autofluorescence Imaging Videobronchoscopy}

Table 1. Research Methods of the 8 Included Studies

\begin{tabular}{|c|c|c|c|c|c|c|c|}
\hline \multirow{2}{*}{ First Author } & \multicolumn{4}{|c|}{ Study Design } & \multicolumn{2}{|c|}{$\begin{array}{c}\text { Autofluorescence Imaging } \\
\text { Videobronchoscopy Was Used For }\end{array}$} & \multirow{2}{*}{$\begin{array}{c}\text { Biopsies Taken From } \\
\text { Cores or Margins of } \\
\text { Suspicious Areas }\end{array}$} \\
\hline & Prospective & Multi-center & Randomized & Controlled & $\begin{array}{l}\text { Diagnosis of Cancerous or } \\
\text { Precancerous Lesions }\end{array}$ & $\begin{array}{l}\text { Assessing Tumor Extent } \\
\text { (margins) }\end{array}$ & \\
\hline Chiyo $^{19}$ & Yes & No & No & No & Yes & No & Cores \\
\hline Ueno $^{50}$ & Yes & No & No & Yes & Yes & No & Cores \\
\hline $\mathrm{Li}^{20}$ & Yes & No & No & Yes & Yes & No & Cores \\
\hline Herth $^{21}$ & Yes & No & No & No & Yes & No & Cores \\
\hline Cetti $^{24}$ & Yes & No & No & Yes & Yes & No & Cores \\
\hline Zaric $^{23}$ & Yes & No & No & Yes & No & Yes & Margins \\
\hline Zaric $^{22}$ & Yes & No & No & Yes & No & Yes & Margins \\
\hline Zaric $^{49}$ & Yes & No & No & Yes & No & Yes & Margins \\
\hline
\end{tabular}

Table 2. Autofluorescence Imaging Videobronchoscopy Versus White-Light Bronchoscopy in the 8 Included Studies

\begin{tabular}{|c|c|c|c|c|c|c|c|c|c|c|c|c|}
\hline \multirow[b]{2}{*}{ First Author } & \multirow[b]{2}{*}{$\begin{array}{l}\text { Pathology } \\
\text { Finding }\end{array}$} & \multirow[b]{2}{*}{$\begin{array}{c}\text { Subjects } \\
\text { no. }\end{array}$} & \multicolumn{5}{|c|}{ Autofluorescence Imaging Videobronchoscopy } & \multicolumn{5}{|c|}{ White-Light Bronchoscopy } \\
\hline & & & $\begin{array}{c}\text { Biopsy } \\
\text { specimens } \\
\text { no. }\end{array}$ & $\begin{array}{c}\text { Positive } \\
\text { no. }\end{array}$ & $\begin{array}{c}\text { Negative } \\
\text { no. }\end{array}$ & $\begin{array}{c}\text { Sensitivity } \\
\%\end{array}$ & $\begin{array}{c}\text { Specificity } \\
\%\end{array}$ & $\begin{array}{c}\text { Biopsy } \\
\text { specimens } \\
\text { no. }\end{array}$ & $\begin{array}{c}\text { Positive } \\
\text { no. }\end{array}$ & $\begin{array}{l}\text { Negative } \\
\text { no. }\end{array}$ & $\begin{array}{c}\text { Sensitivity } \\
\%\end{array}$ & $\begin{array}{c}\text { Specificity } \\
\%\end{array}$ \\
\hline \multirow[t]{2}{*}{ Chiyo $^{19}$} & Dysplasia or worse & 32 & 32 & 26 & 6 & 81.3 & 83.3 & 32 & 18 & 14 & 56.2 & 50 \\
\hline & Bronchitis & & 30 & 5 & 25 & & & 30 & 15 & 15 & & \\
\hline \multirow[t]{2}{*}{ Ueno $^{50}$} & $\begin{array}{l}\text { Severe dysplasia or } \\
\text { worse }\end{array}$ & 31 & 19 & 18 & 1 & 94.7 & 71.1 & 19 & 14 & 5 & 73.7 & 91.1 \\
\hline & Other & & 45 & 13 & 32 & & & 45 & 4 & 41 & & \\
\hline \multirow[t]{2}{*}{$\mathrm{Li}^{20}$} & $\begin{array}{l}\text { Severe dysplasia or } \\
\text { worse }\end{array}$ & 136 & 76 & 72 & 4 & 94.7 & 57 & 76 & 50 & 26 & 65.8 & 83.6 \\
\hline & Other & & 165 & 71 & 94 & & & 165 & 27 & 138 & & \\
\hline \multirow[t]{2}{*}{ Herth $^{21}$} & $\begin{array}{l}\text { Moderate to severe } \\
\text { dysplasia or } \\
\text { carcinoma } \\
\text { in situ }\end{array}$ & 57 & 17 & 3 & 14 & 64.7 & 40 & 17 & 11 & 6 & 17.6 & 87.5 \\
\hline & $\begin{array}{l}\text { Metaplasia and } \\
\text { mild dysplasia }\end{array}$ & & 40 & 5 & 35 & & & 40 & 24 & 16 & & \\
\hline \multirow[t]{2}{*}{ Cetti $^{24}$} & $\begin{array}{l}\text { Moderate dysplasia } \\
\text { or worse }\end{array}$ & 49 & 16 & 15 & 1 & 93.8 & 81.5 & 16 & 15 & 1 & 93.8 & 92.3 \\
\hline & Other & & 64 & 53 & 11 & & & 65 & 5 & 60 & & \\
\hline \multirow[t]{2}{*}{ Zaric $^{22}$} & Carcinoma & 27 & 40 & 36 & 4 & 90 & 85.3 & 45 & 29 & 16 & 64.4 & 55.5 \\
\hline & Other & & 68 & 10 & 58 & & & 63 & 28 & 35 & & \\
\hline \multirow[t]{2}{*}{ Zaric $^{23}$} & Carcinoma & 104 & 312 & 286 & 26 & 91.7 & 92.6 & 312 & 242 & 70 & 77.6 & 85.3 \\
\hline & Other & & 312 & 23 & 289 & & & 312 & 46 & 266 & & \\
\hline Zaric $^{49}$ & $\begin{array}{l}\text { Carcinoma } \\
\text { Other }\end{array}$ & 118 & & & & 89.1 & 77.8 & & & & 76.8 & 51.9 \\
\hline
\end{tabular}

lesions, with the hope that early treatment would improve outcomes. We see some possible explanations for the observation that AFI might be superior over WLB in detection of pre-invasive lesions such as dysplasia, but not to the same degree in detecting invasive cancer. The quality of WLB images has improved with the advent of the videobronchoscope, and most of invasive cancers that can be detected by AFI also could be detected by WLB. But the situation is different for pre-invasive lesions. WLB is ineffective at detecting lesions smaller than $5 \mathrm{~mm}$ in di- ameter, and pre-invasive lesions are only a few cell layers thick, so the surface mucosa typically appears relatively normal during WLB. AFI can detect tiny and superficial lesions, thereby improving diagnostic sensitivity for earlystage lesions. ${ }^{28,29}$ On the other hand, the conflicting findings about AFI's sensitivity and specificity can partly be ascribed to the use of different definitions of positive histology and different endoscopy classifications. Ueno et al ${ }^{50}$ considered AFI-III (image appeared magenta) as positive in AFI, and the sensitivity and specificity of AFI for severe 


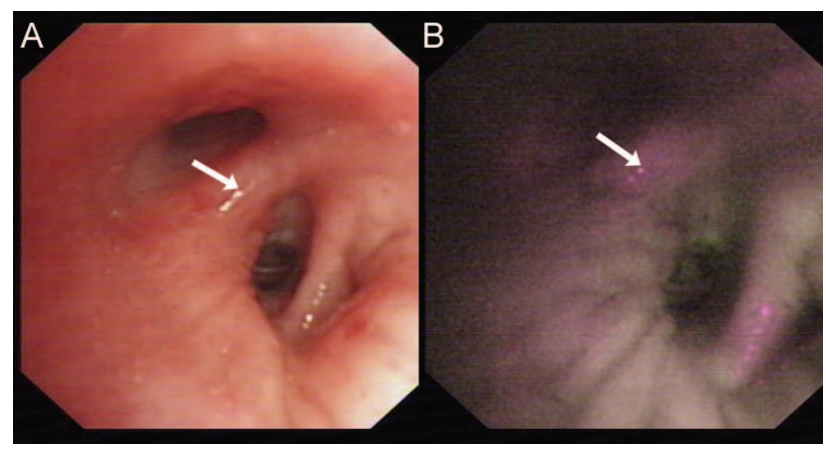

Fig. 2. Bronchoscopy at the bifurcation of the right middle lobe and lower lobe. A: White-light bronchoscopy shows non-specific swelling or thickening (arrow), which might be judged normal and not biopsied. B: Autofluorescence imaging videobronchoscopy shows magenta color that indicates mucosal abnormality, which pathology found was adenocarcinoma.

dysplasia or worse were $94.7 \%$ and $71.1 \%$, respectively. Chiyo et al, ${ }^{19}$ defined AFI-II (images appeared pinkishbrown) and AFI-III (images appeared magenta) as positive, and the sensitivity and specificity of AFI for dysplasia or worse were $81.3 \%$ and $83.3 \%$, respectively. If Ueno et $\mathrm{al}^{50}$ analyzed data according to the criteria used by Chiyo et al, the sensitivity and specificity for AFI would be $76.7 \%$ (23/30) and $83.0 \%$ (15/18). Furthermore, the sensitivity and specificity of AFI or WLB can be changed by the statistical unit, using the patient or the lesion as different statistical units for analysis. For the per-patient analysis, one patient usually has several biopsied lesions; the highest grade lesion can be used to determine the patient's overall histological diagnosis. For the per-lesion analysis, each biopsied lesion is independently evaluated endoscopically with AFI or WLB, and each specimen would be defined as positive independently if its own final histology diagnosis is considered positive in the study. Edell et al reported ${ }^{11}$ that the relative sensitivity of AFB + WLB versus WLB was 1.50 on a per-lesion basis (95\% CI 1.261.89 ) and 1.33 (95\% CI 1.13-1.70) on per-patient basis. In the studies $18,19,22-24,50$ we analyzed, only the study by Herth et $\mathrm{al}^{21}$ used per-patient analysis to evaluate the sensitivity and specificity of AFI or WLB. In that study, if a patient had 2 separate positive biopsy sites, one site showing moderate dysplasia and the other showing severe dysplasia, the patient's overall histology result was severe dysplasia.

In our own experience, AFI is more sensitive for detecting superficial lung cancers and precancerous lesions than is WLB. Some lesions can be recognized via AFI when the WLB findings are normal (Fig. 2). But AFI may be less specific, and may have more false positive results if we do not choose proper indications for AFI. Some benign lesions, such as inflammatory bronchial lesions or

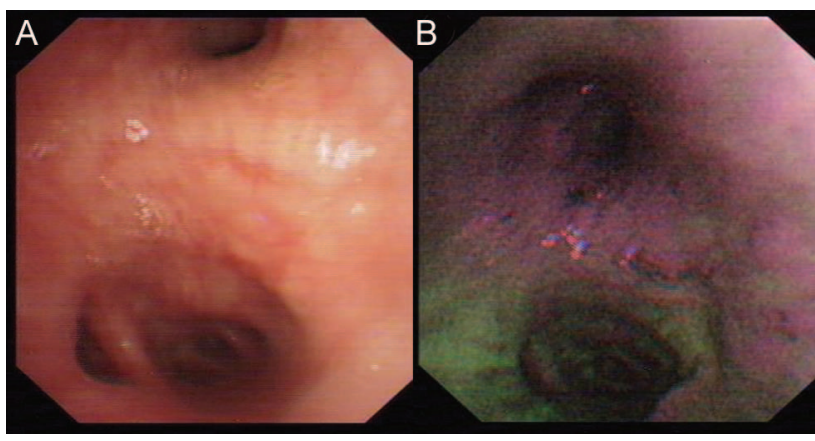

Fig. 3. Bronchoscopy at the bifurcation of the left upper lobe and lower lobe. A: White-light bronchoscopy shows edema or thickening. B: Autofluorescence imaging videobronchoscopy image shows magenta color that indicates mucosal abnormality. Pathology with acid-fast stain led to a diagnosis of tuberculosis.

tuberculosis, also appear as magenta on the AFI monitor (Fig. 3). AFI cannot identify a lesion's pathology. It distinguishes optical properties of the surface tissues based on their thickness, blood supply, or extracellular matrix composition, which may be nonspecifically responded in AFI. It is not easy to distinguish benign lesions such as inflammation, hyperemia, or injury from pre-invasive carcinoma, so the specificity for AFI may be low. The low specificity and high false positive rate may result in a greater number of abnormal lesions being identified during bronchoscopy, prolonging the procedure in order to biopsy the lesions, and thus increasing the number of specimens and pathology costs. The AFI system is also about twice as expensive as a WLB system. AFI and its work station cost our department about US\$192,000 (¥1,200,000 China renminbi), whereas a WLB system and work station cost about US $\$ 96,000$ ( $¥ 600,000$ China renminbi). So we should strictly control the indications for AFI. There are no universally accepted indications for AFB. However, suggested indications include the evaluation of patients who have high-grade sputum atypia but no radiological abnormalities, surveillance of patients with previously detected high-grade pre-invasive lesions (metaplasia, dysplasia, carcinoma in situ) but no evidence of invasive carcinoma, and planning endobronchial therapy for patients who have early invasive lung cancer.

The false positive rate of AFI may be decreased through objective color tone analysis. Chiyo et $\mathrm{al}^{19}$ used color tone analysis to resolve the image color into the 3 primary colors: red, green, and blue. For moderate dysplasia the mean intensities of the red, green, and blue signals were $42.19 \pm 12.19$ pixels, $30.5 \pm 2.56$ pixels, and $21.31 \pm$ 3.98 pixels, respectively, and the red/green ratio of the mean intensities was $1.38(42.19 / 30.5)$. For bronchitis the mean intensities were $28.6 \pm 3.53$ pixels, $38.5 \pm 1.7$ pixels, and $24.7 \pm 1.0$ pixels, respectively, and the red/green ratio was $0.74(28.6 / 38.5)$. The red/green ratio was higher 


\section{Value of Autofluorescence Imaging Videobronchoscopy}

Table 3. Studies of Autofluorescence Bronchoscopy Versus White-Light Bronchoscopy

\begin{tabular}{|c|c|c|c|c|c|c|c|c|}
\hline \multirow{2}{*}{ First Author } & \multirow{2}{*}{$\begin{array}{l}\text { Autofluorescence } \\
\text { Bronchoscopy } \\
\text { System }\end{array}$} & \multirow{2}{*}{$\begin{array}{l}\text { Histology Considered } \\
\text { Positive If: }\end{array}$} & \multirow{2}{*}{$\begin{array}{l}\text { Subjects } \\
\text { (no.) }\end{array}$} & \multirow{2}{*}{$\begin{array}{l}\text { Biopsy } \\
\text { Specimens } \\
\text { (no.) }\end{array}$} & \multicolumn{2}{|c|}{$\begin{array}{l}\text { Autofluorescence } \\
\text { Bronchoscopy }\end{array}$} & \multicolumn{2}{|c|}{$\begin{array}{l}\text { White-Light } \\
\text { Bronchoscopy }\end{array}$} \\
\hline & & & & & $\begin{array}{c}\text { Sensitivity } \\
(\%)\end{array}$ & $\begin{array}{c}\text { Specificity } \\
(\%)\end{array}$ & $\begin{array}{c}\text { Sensitivity } \\
(\%)\end{array}$ & $\begin{array}{c}\text { Specificity } \\
(\%)\end{array}$ \\
\hline Edell $^{11}$ & Onco-LIFE & $\begin{array}{l}\text { Moderate to severe dysplasia } \\
\text { or carcinoma in situ }\end{array}$ & 170 & 776 & 32 & 75 & 10 & 94 \\
\hline Kakihana $^{10}$ & SAFE 1000 & Mild dysplasia or worse & 72 & 147 & 92 & 56 & 66 & 54 \\
\hline $\mathrm{Lam}^{41}$ & SAFE 1000 & Moderate dysplasia or worse & 62 & 84 & 91 & 26 & 58 & 50 \\
\hline Chhajed $^{40}$ & LIFE & Moderate dysplasia or worse & 151 & 343 & 96 & 23 & 72 & 53 \\
\hline Venmans $^{13}$ & LIFE & Moderate dysplasia or worse & 95 & 681 & 80 & 62 & 59 & 85 \\
\hline Ikeda $^{45}$ & LIFE & Mild dysplasia or worse & 158 & 262 & 95 & 67 & 73 & 62 \\
\hline Ikeda $^{38}$ & LIFE & Dysplasia & 30 & & 50 & 84 & 31 & 88 \\
\hline & & Cancer & & & 97 & & 90 & \\
\hline
\end{tabular}

in squamous dysplasia than in bronchitis. They concluded that AFI with color tone analysis could accurately and objectively distinguish pre-invasive and malignant lesions from bronchitis.

\section{Diagnostic Performance of AFI Versus Other AFBs}

Table 3 describes studies that have compared the diagnostic yield of AFB to that of WLB. A meta-analysis concluded that AFB has a higher sensitivity and lower specificity than WLB, but there has been only direct comparison of AFI and another AFB. Chiyo et al ${ }^{19}$ compared AFI to the LIFE AFB device for distinguishing preinvasive bronchial lesions from bronchitis. A total of 32 patients with known or suspected lung cancer were included. WLB and LIFE were performed prior to AFI. WLB and LIFE detected 62 lesions, including lung cancers $(n=2)$, squamous dysplasias $(n=30)$, and bronchitis $(n=30)$. With AFI, 2 cancer lesions and 24 dysplasias were magenta in color, and 25 bronchitis lesions were blue. The sensitivity for detecting dysplasia with LIFE was $96.7 \%$, and with AFI it was $80 \%$. The specificity of AFI $(83.3 \%)$ was significantly higher than that of LIFE (36.6\%) $(P<=.001)$. They concluded that AFI with color tone analysis can accurately and objectively distinguish preinvasive and malignant lesions from bronchitis. However, because comparative data between AFI and other AFBs are scarce, there are many unanswered questions about the differences between AFI and other AFBs.

\section{Diagnostic Performance of AFI Versus Narrow-Band Imaging}

Angiogenesis is essential for malignant neoplasm, which was first recognized by Folkman, ${ }^{51}$ because a hyperproliferated tissue requires adequate blood supply. Increased vessel density in the submucosa is often present in bron- chial squamous dysplasia, ${ }^{52,53}$ indicating that angiogenesis is a relatively early event during lung cancer pathogenesis. $^{54}$

NBI is a new optical technology that can clearly visualize the microvascular structure on mucosal surfaces, ${ }^{55,56}$ using a new narrow banding filter on an red/green/blue sequential videoscope system, instead of the conventional red/green/blue broadband filter. The filter cuts all wavelengths in illumination except for narrow bands in the blue and green spectrum, centered at $415 \mathrm{~nm}$ and $540 \mathrm{~nm}$, coinciding with the peak absorption spectrum of oxyhemoglobin (the main chromophore in bronchial tissues), ${ }^{57}$ making blood vessels more pronounced when viewed in NBI mode. ${ }^{58}$ The $415 \mathrm{~nm}$ blue light is absorbed by capillary vessels in the surface layer of the mucosa, whereas the $540 \mathrm{~nm}$ wavelength is strongly absorbed by blood vessels located below the capillary vessels in the surface layer of the mucosa. Finer blood vessels near the surface are displayed in brown, whereas thicker vessels in deeper layers are shown in cyan. Bleeding appears in black, because the $415 \mathrm{~nm}$ and $540 \mathrm{~nm}$ wavelengths are largely absorbed by hemoglobin. ${ }^{59}$ Tissue optical absorption properties and scattering properties are strongly wavelength dependent. When conventional red/green/blue broadband light is delivered through an endoscope onto a tissue surface, some of the light is reflected from the tissue, some is scattered or absorbed within the tissue, and very little light is reflected toward the camera lens to provide an image. However, narrow band light delivered onto the same surface has less scattering, which provides a clearer image. ${ }^{60}$

An approach to visualize angiogenesis or aberrant microvessels in the subepithelial cancerous lesion can be a new diagnostic method. There are growing numbers of reports on the effectiveness of NBI for detailed observation of the superficial mucosal and vascular patterns in the laryn $\mathrm{x}^{61}$ and gastrointestinal tract. ${ }^{55,62-66}$ After successful introduction into gastroenterology and confirmation on its 


\section{Value of Autofluorescence Imaging Videobronchoscopy}

value in diagnosis of gastrointestinal malignancies, NBI entered the area of diagnostic and interventional pulmonology. ${ }^{58,67-70}$ There have been few direct comparisons of NBI and AFI. Some studies used NBI to evaluate localized sites of interest that were detected with AFB. ${ }^{60}$ A recent study by Herth et $\mathrm{al}^{21}$ evaluated the diagnostic yields of NBI individually and in combination with WLB and AFI. Both NBI and AFI had superior sensitivities, compared with WLB alone, and there was no significant difference in sensitivity between NBI and AFI. There was no significant difference in specificity between NBI and WLB, but AFI's specificity was significantly lower than either NBI or WLB. That study concluded that NBI is an alternative to AFI for detecting early lung cancers, because NBI has higher specificity and comparable sensitivity. Further investigation is required on NBI versus AFI.

\section{Summary}

The sensitivity of AFI seems to be better than that of WLB, but whether AFI's specificity is higher or lower than that of WLB is still in controversy. A few original studies and meta-analyses have investigated the diagnostic yield of AFBs versus WLB, and most of them concluded that AFB has a higher sensitivity and lower specificity than WLB. Comparative data between AFI and other AFBs are scarce, so it remains unclear whether AFI is superior to other AFBs. And further comparative data between NBI and AFI are still needed to draw conclusions on the superiority of one technique over the other.

In clinical practice, the potential extra sensitivity provided by AFI, to some extent, improves the ability of trainees to make the correct diagnosis at bronchoscopy, and suggests a role for AFI in teaching hospitals for training inexperienced bronchoscopists. ${ }^{24}$ AFI and WLB are incorporated into one endoscope system, and it is easy to switch between the 2 modes. The addition of AFI does not significantly increase adverse effects that can be attributable to the AFI observation. ${ }^{20,21}$ According to the literature and our own experience, the major down sides to AFI are the lower specificity, higher false positive rate (which increases the number of biopsy sites and causes more mucosal injuries), higher costs, and longer examination time. The false positive rate with AFI can be decreased with objective color tone analysis. Although AFI seemed to provide advantages in some studies, in our opinion the benefit in clinical practice is not overwhelming. AFI should be utilized in patients who have high-grade sputum atypia but no radiological abnormalities, surveillance of patients with previously detected high-grade preinvasive lesions (metaplasia, dysplasia, carcinoma in situ) but no evidence of invasive carcinoma, and in planning endobronchial therapy for patients who have early invasive lung cancer.

\section{ACKNOWLEDGMENTS}

We are grateful to Danielle Speer and Ambrose Chiang, Division of Pulmonary and Critical Care Medicine, Duke University Medical Center, Durham, North Carolina, for information and correction.

\section{REFERENCES}

1. Ezzati M, Lopez AD. Estimates of global mortality attributable to smoking in 2000. Lancet 362(9387):847-52, 2003 Sep 13.

2. Mountain CF. Revisions in the international system for staging lung cancer. Chest 1997;111(6):1710-1717.

3. Woolner LB, Fontana RS, Cortese DA, Sanderson DR, Bernatz PE, Payne WS, et al. Roentgenographically occult lung cancer: pathologic findings and frequency of multicentricity during a 10-year period. Mayo Clin Proc 1984;59(7):453-466.

4. Thiberville L, Payne P, Vielkinds J, LeRiche J, Horsman D, Nouvet $\mathrm{G}$, et al. Evidence of cumulative gene losses with progression of premalignant epithelial lesions to carcinoma of the bronchus. Cancer Res 1995;55(22):5133-5139.

5. Bota S, Auliac JB, Paris C, Métayer J, Sesboüé R, Nouvet G, Thiberville L. Follow-up of bronchial precancerous lesions and carcinoma in situ using fluorescence endoscopy. Am J Respir Crit Care Med 2001;164(9):1688-1693.

6. Edell ES, Cortese DA. Photodynamic therapy in the management of early superficial squamous cell carcinoma as an alternative to surgical resection. Chest 1992;102(5):1319-1322.

7. Anderson GH, Boyes DA, Benedet JL, Le Riche JC, Matisic JP, Suen KC, et al. Organisation and results of the cervical cytology screening programme in British Columbia, 1955-85. BMJ (Clin Res Ed) 1988;296(6627):975-978

8. Winawer SJ, Zauber AG, O'Brien MJ, Ho MN, Gottlieb L, Sternberg SS, et al. Randomized comparison of surveillance intervals after colonoscopic removal of newly diagnosed adenomatous polyps. The National Polyp Study Workgroup. N Engl J Med 1993;328(13): 901-906.

9. Lam S, MacAulay C, leRiche JC, Palcic B. Detection and localization of early lung cancer by fluorescence bronchoscopy. Cancer 2000;89(11 Suppl):2468-2473.

10. Kakihana M, Il KK, Okunaka T, Furukawa K, Hirano T, Konaka C, et al. Early detection of bronchial lesions using system of autofluorescence endoscopy (SAFE) 1000. Diagn Ther Endosc 1999;5(2): 99-104.

11. Edell E, Lam S, Pass H, Miller YE, Sutedja T, Kennedy T, et al. Detection and localization of intraepithelial neoplasia and invasive carcinoma using fluorescence-reflectance bronchoscopy: an international, multicenter clinical trial. J Thorac Oncol 2009; 4(1):49-54. Erratum in: J Thorac Oncol 2009;4(4):558.

12. Jang TW, Oak CH, Chun BK, Jung MH. Detection of pre-invasive endobronchial tumors with D-light/autofluorescence system. J Korean Med Sci 2006;21(2):242-246.

13. Venmans BJ, Van Boxem TJ, Smit EF, Postmus PE, Sutedja TG. Results of two years expenience with fluorescence bronchoscopy in detection of preinvasive bronchial neoplasia. Diagn Ther Endosc 1999;5(2):77-84.

14. Kusunoki Y, Imamura F, Uda H, Mano M, Horai T. Early detection of lung cancer with laser-induced fluorescence endoscopy and spectrofluorometry. Chest 2000;118(6):1776-1782.

15. Hirsch FR, Prindiville SA, Miller YE, Franklin WA, Dempsey EC, Murphy JR, et al. Fluorescence versus white-light bronchoscopy for detection of preneoplastic lesions: a randomized study. J Natl Cancer Inst 2001;93(18):1385-1391.

16. Hirsch FR, Franklin WA, Gazdar AF, Bunn PA Jr. Early detection of lung cancer: clinical perspectives of recent advances in biology and radiology. Clin Cancer Res 2001;7(1):5-22. 


\section{Value of Autofluorescence Imaging Videobronchoscopy}

17. Chen W, Gao X, Tian Q, Chen L. A comparison of autofluorescence bronchoscopy and white light bronchoscopy in detection of lung cancer and preneoplastic lesions: a meta-analysis. Lung Cancer 2011; 73(2):183-188.

18. Sun J, Garfield DH, Lam B, Yan J, Gu A, Shen J, Han B. The value of autofluorescence bronchoscopy combined with white light bronchoscopy compared with white light alone in the diagnosis of intraepithelial neoplasia and invasive lung cancer: a meta-analysis. J Thorac Oncol 2011;6(8):1336-1344.

19. Chiyo M, Shibuya K, Hoshino H, Yasufuku K, Sekine Y, Iizasa T, et al. Effective detection of bronchial preinvasive lesions by a new autofluorescence imaging bronchovideoscope system. Lung Cancer 2005;4(3):307-313.

20. Li Y, Li X, Sui XZ, Bu L, Zhou ZL, Yang F, et al. Comparison of the autofluorescence bronchoscope and the white light bronchoscope in airway examination. Chin J Cancer 2010;29(12):1018-1022.

21. Herth FJ, Eberhardt R, Anantham D, Gompelmann D, Zakaria MW, Ernst A. Narrow-band imaging bronchoscopy increases the specificity of bronchoscopic early lung cancer detection. J Thorac Oncol 2009;4(9):1060-1065.

22. Zaric B, Canak V, Stojanovic G, Jovelic A, Sarcev T, Kuruc V, et al. Autofluorescence videobronchoscopy (AFI) for the assessment of tumor extension in lung cancer. Technol Cancer Res Treat 2009; 8(1):79-84

23. Zaric B, Becker HD, Perin B, Stojanovic G, Jovelic A, Eri Z, et al. Autofluorescence imaging videobronchoscopy improves assessment of tumor margins and affects therapeutic strategy in central lung cancer. Jpn J Clin Oncol 2010;40(2):139-145.

24. Cetti EJ, Nicholson AG, Singh S, Wells AU, Shah PL. An evaluation of a videobronchoscopy-based autofluorescence system in lung cancer. Eur Respir J 2010;35(5):1185-1187.

25. Palcic B, Lam S, Hung J, MacAulay C. Detection and localization of early lung cancer by imaging techniques. Chest 1991;99(3):742-743.

26. von Holstein CS, Nilsson AM, Andersson-Engels S, Willén R, Walther B, Svanberg K. Detection of adenocarcinoma in Barrett's oesophagus by means of laser induced fluorescence. Gut 1996;39(5): 711-716.

27. Hung J, Lam S, LeRiche JC, Palcic B. Autofluorescence of normal and malignant bronchial tissue. Lasers Surg Med 1991;11(2):99-105.

28. Lam S, MacAulay C, Hung J, LeRiche J, Profio AE, Palcic B. Detection of dysplasia and carcinoma in situ with a lung imaging fluorescence endoscope device. J Thorac Cardiovasc Surg 1993; 105(6): 1035-1040.

29. Lam S, Macaulay C, Leriche JC, Ikeda N, Palcic B. Early localization of bronchogenic carcinoma. Diagn Ther Endosc 1994;1(2): 75-78.

30. Lam S, Kennedy T, Unger M, Miller YE, Gelmont D, Rusch V. Localization of bronchial intraepithelial neoplastic lesions by fluorescence bronchoscopy. Chest 1998;113(3):696-702.

31. Leonhard M. New incoherent autofluorescence/fluorescence system for early detection of lung cancer. Diagn Ther Endosc 1999;5(2): 71-75.

32. Adachi R, Utsui T, Furusawa K. Development of the autofluorescence endoscope imaging system. Diagn Ther Endosc 1999;5(2): 65-70.

33. Ikeda N, Honda H, Hayashi A, Usuda J, Kato Y, Tsuboi M, et al. Early detection of bronchial lesions using newly developed videoendoscopy-based autofluorescence bronchoscopy. Lung Cancer 2006; 52(1):21-27

34. Zellweger M, Grosjean P, Goujon D, Monnier P, van den Bergh H, Wagnières G. In vivo autofluorescence spectroscopy of human bronchial tissue to optimize the detection and imaging of early cancers. J Biomed Opt 2001;6(1):41-51.
35. Qu J, Macaulay C, Lam S, Palcic B. Optical properties of normal and carcinomatous bronchial tissue. Appl Opt 1994;33(31):7397-7405. DOI: 10.1364/AO.33.007397.

36. Bolon I, Brambilla E, Vandenbunder B, Robert C, Lantuejoul S, Brambilla $\mathrm{C}$. Changes in the expression of matrix proteases and of the transcription factor c-Ets-1 during progression of precancerous bronchial lesions. Lab Invest 1886;75(1):1-13.

37. Shibuya K, Fujisawa T, Hoshino H, Baba M, Saitoh Y, Iizasa T, et al. Fluorescence bronchoscopy in the detection of preinvasive bronchial lesions in patients with sputum cytology suspicious or positive for malignancy. Lung Cancer 2001;32(1):19-25.

38. Ikeda N, Hiyoshi T, Kakihana M, Honda H, Kato Y, Okunaka T, et al. Histopathological evaluation of fluorescence bronchoscopy using resected lungs in cases of lung cancer. Lung Cancer 2003;41(3): 303-309.

39. Loizzi M, De Palma A, Lacitignola A, Genualdo M, Loizzi D, Capotorto $\mathrm{G}$ et al. Autofluorescence bronchoscopy in early diagnosis of pulmonary carcinoma. Minerva Chir 2005;60(6):497-503.

40. Chhajed PN, Shibuya K, Hoshino H, Chiyo M, Yasufuku K, Hiroshima K, Fujisawa T. A comparison of video and autofluorescence bronchoscopy in patients at high risk of lung cancer. Eur Respir J 2005;25(6):951-955.

41. Lam B, Wong MP, Fung SL, Lam DC, Wong PC, Mok TY, et al. The clinical value of autofluorescence bronchoscopy for the diagnosis of lung cancer. Eur Respir J 2006;28(5):915-919.

42. Nakanishi K, Ohsaki Y, Kurihara M, Nakao S, Fujita Y, Takeyama $\mathrm{K}$, et al. Color auto-fluorescence from cancer lesions: improved detection of central type lung cancer. Lung Cancer 2007;58(2): 214-219.

43. Häußinger K, Stanzel F, Huber RM, Pichler J, Stepp H. Autofluorescence detection of bronchial tumors with the D-Light/AF. Diagn Ther Endosc 1999;5(2):105-112.

44. Horvath T, Horvathova M, Salajka F, Habanec B, Foretova L, Kana $\mathrm{J}$, et al. Detection of bronchial neoplasia in uranium miners by autofluorescence endoscopy (SAFE-1000). Diagn Ther Endosc 1999; 5(2):91-98.

45. Ikeda N, Honda H, Katsumi T, Okunaka T, Furukawa K, Tsuchida $\mathrm{T}$, et al. Early detection of bronchial lesions using lung imaging fluorescence endoscope. Diagn Ther Endosc 1999;5(2):85-90.

46. Häussinger K, Becker H, Stanzel F, Kreuzer A, Schmidt B, Strausz $\mathrm{J}$, et al. Autofluorescence bronchoscopy with white light bronchoscopy compared with white light bronchoscopy alone for the detection of precancerous lesions: a European randomised controlled multicentre trial. Thorax 2005;60(6):496-503.

47. Moro-Sibilot D, Jeanmart M, Lantuejoul S, Arbib F, Laverrière MH, Brambilla E, Brambilla C. Cigarette smoking, preinvasive bronchial lesions, and autofluorescence bronchoscopy. Chest 2002;122(6): 1902-1908.

48. van Rens MT, Schramel FM, Elbers JR, Lammers JW. The clinical value of lung imaging fluorescence endoscopy for detecting synchronous lung cancer. Lung Cancer 2001;32(1):13-18.

49. Zaric B, Perin B, Becker HD, Herth FF, Eberhardt R, Jovanovic S, et al. Combination of narrow band imaging (NBI) and autofluorescence imaging (AFI) videobronchoscopy in endoscopic assessment of lung cancer extension. Med Oncol 2012;29(3):1638-1642.

50. Ueno K, Kusunoki Y, Imamura F, Yoshimura M, Yamamoto S, Uchida J, Tsukamoto Y. Clinical experience with autofluorescence imaging system in patients with lung cancers and precancerous lesions. Respiration 2007;74(3):304-308.

51. Folkman J. What is the evidence that tumors are angiogenesis dependent? J Natl Cancer Inst 1990;82(1):4-6.

52. Fisseler-Eckhoff A, Rothstein D, Müller KM. Neovascularization in hyperplastic, metaplastic and potentially preneoplastic lesions of the bronchial mucosa. Virchows Arch 1996;429(2-3):95-100. 


\section{Value of Autofluorescence Imaging Videobronchoscopy}

53. Fontanini G, Calcinai A, Boldrini L, Lucchi M, Mussi A, Angeletti CA, et al. Modulation of neoangiogenesis in bronchial preneoplastic lesions. Oncol Rep 1999;6(4):813-817.

54. Gazdar AF, Minna JD. Angiogenesis and the multistage development of lung cancers. Clin Cancer Res 2000;6(5):1611-1612.

55. Gono K, Obi T, Yamaguchi M, Ohyama N, Machida H, Sano Y, et al. Appearance of enhanced tissue features in narrow-band endoscopic imaging. J Biomed Opt 2004;9(3):568-577.

56. Gono K, Igarashi M, Obi T, Yamaguchi M, Ohyama N. Multiplediscriminant analysis for light-scattering spectroscopy and imaging of two-layered tissue phantoms. Opt Lett 2004;29(9):971-973.

57. Smith MH, Denninghoff KR, Lompado A, Hillman LW. Effect of multiple light paths on retinal vessel oximetry. Appl Opt 2000;39(7): 1183-1193.

58. Vincent BD, Fraig M, Silvestri GA. A pilot study of narrow-band imaging compared to white light bronchoscopy for evaluation of normal airways and premalignant and malignant airways disease. Chest 2007;131(6):1794-1799.

59. East JE, Suzuki N, Bassett P, Stavrinidis M, Thomas HJ, Guenther $\mathrm{T}$, et al. Narrow band imaging with magnification for the characterization of small and diminutive colonic polyps: pit pattern and vascular pattern intensity. Endoscopy 2008;40(10):811-817.

60. Shibuya K, Hoshino H, Chiyo M, Iyoda A, Yoshida S, Sekine Y, et al. High magnification bronchovideoscopy combined with narrow band imaging could detect capillary loops of angiogenic squamous dysplasia in heavy smokers at high risk for lung cancer. Thorax 2003;58(11):989-995.

61. Muto M, Katada C, Sano Y, Yoshida S. Narrow band imaging: a new diagnostic approach to visualize angiogenesis in superficial neoplasia. Clin Gastroenterol Hepatol 2005;3(7 Suppl 1): S16-S20.
62. Yoshida T, Inoue H, Usui S, Satodate H, Fukami N, Kudo SE. Narrow-band imaging system with magnifying endoscopy for superficial esophageal lesions. Gastrointest Endosc 2004;59(2): 288-295.

63. Hamamoto Y, Endo T, Nosho K, Arimura Y, Sato M, Imai K. Usefulness of narrow-band imaging endoscopy for diagnosis of Barrett's esophagus. J Gastroenterol 2004;39(1):14-20.

64. Nakayoshi T, Tajiri H, Matsuda K, Kaise M, Ikegami M, Sasaki H. Magnifying endoscopy combined with narrow band imaging system for early gastric cancer: correlation of vascular pattern with histopathology (including video). Endoscopy 2004;36(12):1080-1084.

65. Kuznetsov K, Lambert R, Rey JF. Narrow-band imaging: potential and limitations. Endoscopy 2006;38(1):76-81.

66. Kara MA, Ennahachi M, Fockens P, ten Kate FJ, Bergman JJ. Detection and classification of the mucosal and vascular patterns (mucosal morphology) in Barrett's esophagus by using narrow band imaging. Gastrointest Endosc 2006;64(2):155-166.

67. Shibuya K, Hoshino H, Chiyo M, Yasufuku K, Iizasa T, Saitoh Y, et al. Subepithelial vascular patterns in bronchial dysplasias using a high magnification bronchovideoscope. Thorax 2002;57(10): 902-907.

68. Yamada G, Kitamura Y, Kitada J, Yamada Y, Takahashi M, Fujii M, Takahashi H. Increased microcirculation in subepithelial invasion of lung cancer. Intern Med 2011;50(8):839-843.

69. Shibuya K, Nakajima T, Fujiwara T, Chiyo M, Hoshino H, Moriya $\mathrm{Y}$, et al. Narrow band imaging with high-resolution bronchovideoscopy: a new approach for visualizing angiogenesis in squamous cell carcinoma of the lung. Lung Cancer 2010;69(2):194-202.

70. Zaric B, Becker HD, Perin B, Jovelic A, Stojanovic G, Ilic MD, et al. Narrow band imaging videobronchoscopy improves assessment of lung cancer extension and influences therapeutic strategy. Jpn J Clin Oncol 2009;39(10):657-663. 